\title{
DIÁLOGOS CRÍTICOS CON SISTEMAS COMPLEJOS
}

\section{CRITICAL DIALOGUES WITH COMPLEX SYSTEMS}

\author{
LARA SÁnchez Coterón / larasanc@ucm.es \\ Grupo Investigación Prácticas artísticas y formas de conocimiento contemporáneas. \\ Facultad de Bellas Artes. Universidad Complutense de Madrid. España
}

Recibido:16/5/2020 | Aceptado:23/8/2020

\section{RESUMEN}

El arte y el diseño en la era digital están estrechamente vinculados a modelos y estructuras sistémicas en lo formal y lo discursivo. Entendiendo este tipo de hibridaciones entre arte y ciencia (estudios de sistemas) como punto de partida para pensar en la activación, reconfiguración o generación de sistemas complejos como recurso artístico, este artículo reflexiona sobre las posibilidades de crear discurso desobediente, de superponerse y problematizar las ontologías políticas de los sistemas normativos en esa confluencia. La investigación utiliza la teoría los puntos críticos de intervención sobre sistemas complejos de la científica D. H. Meadows, como marco referencial y como pretexto para analizar los diversos modos de generar experiencia significativa y semánticas disruptivas que utilizan los artistas y los diseñadores contemporáneos.

\section{PALABRAS CLAVE}

Sistemas no naturales; arte de los nuevos medios; diseño de interacción; prácticas críticas

\section{ABSTRACT}

Art and design in the digital age are closely linked to systemic models and structures both formally and discursively. The research takes this type of hybridization between art and science (systems studies) as a starting point to investigate about the activation, reconfiguration or creation of complex systems as an artistic resource. This article analyses the possibilities of creating disobedient discourse by overlapping and problematizing the political ontologies of normative systems at this confluence. The research builds on the Leverage Points approach by American environmental scientist D. H. Meadows to dissect the various ways of producing significant experience and disruptive semantics used by contemporary artists and designers.

\section{KEYWORDS}

Artificial systems; new media art; interaction design; critical practices 


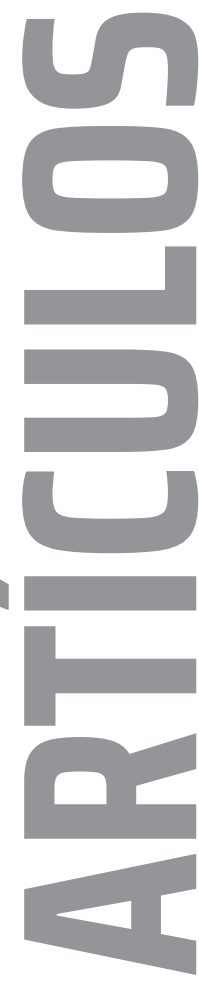

Vivimos inmersos y nos relacionamos con diferentes sistemas adaptativos complejos desde mucho antes de la incursión de las computadoras en nuestra cotidianidad. Algunos de corte natural como el cerebro, los sistemas inmunes o los sistemas ecológicos. Otros sociales como los partidos políticos o los mercados bursátiles (Miller \& Page, 2007). Es con la aparición de los sistemas de naturaleza artificial —sistemas informáticos paralelos y distribuidos, sistemas de inteligencia artificial, redes neuronales artificiales, programas evolutivos, etcétera- cuando de manera explícita los conceptos y los procesos de los sistemas complejos comienzan a ser estudiados desde su perspectiva propia mediante Estudios y Teoría de Sistemas — cibernética o Sistemas Complejos Adaptativos (CAS) — para más tarde permear, a la par que las tecnologías computacionales con los que se construyen, en el mundo del arte. En este marco contemporáneo las nociones de emergencia, criticidad autoorganizada, autómatas celulares, redes, diversidad, adaptación y retroalimentación son fundamentales para comprender el contexto del arte de los nuevos medios.

Desde la óptica formal, ya en 1997 Janet H. Murray define, en su libro Hamlet on the Holodeck [Hamlet en la holocubierta], la proceduralidad como una de las propiedades esenciales de los artefactos digitales (junto con la participación, la espacialidad y el alcance enciclopédico). La autora usa el término de procedural para referirse a la "capacidad definitoria de la computadora para ejecutar una serie de reglas» (Murray, 1997, p. 73).

La proceduralidad, en este sentido, se refiere a la propia epistemología de los lenguajes lógicos. El código informático está compuesto por algoritmos que modelan sistemas y definen la forma en que se comportan las cosas. Las prácticas artísticas computacionales de los años noventa, software art, net art, game art, etcétera, comienzan a trabajar con y desde este tipo de materiales y conceptos, en ocasiones a modo de réplica o representación, para rápidamente abrir nuevas posibilidades discursivas. Nuevas relaciones de reconfiguración e intervención de los artistas y diseñadores sobre estructuras sistémicas no naturales que generan relatos con determinación contestataria y de desacuerdo con las políticas integradas en esas configuraciones procedurales.

Las máquinas, como apuntaba Gilles Deleuze (1992) en su breve texto Postscript on the Societies of Control [Posdata sobre las sociedades de control], son fácilmente emparentables con cada tipo de sociedad, debido a cómo expresan las formas sociales capaces de generarlas y usarlas. Las máquinas computacionales, por extensión, parecen estar expresando y representando mediante su gramática sistémica el imaginario social del mundo contemporáneo conectado y sus diversas estructuras de organización y regulación. 


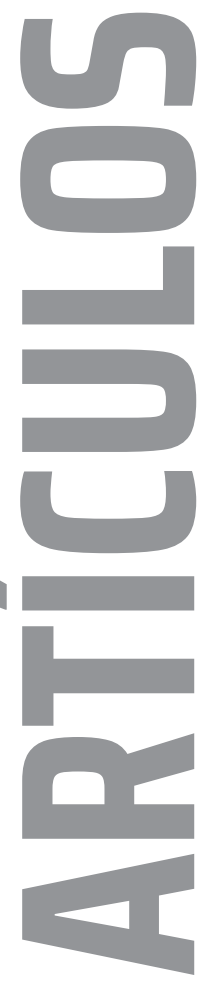

Mientras que a principios de los años 2000, y posiblemente en un estado de expectativas sobre escaladas en relación con esa nueva realidad de computación e interconexión global, el artista y teórico de los nuevos medios Lev Manovich (2001) argumentaba que los medios digitales, sus principios, sus fundamentos, sus métodos, podían ser el principio del fin para las funciones de persuasión de la retórica clásica (oral, escrita, visual), desde el ámbito de los estudios de juegos autores como Alexander R. Galloway (2006) ponían en tela de juicio las políticas inscritas en un objeto cultural algorítmico paradigmático como son los juegos digitales. Galloway (2006) se refiere a los videojuegos como «una alegoría de la estructura algorítmica y de control de la actual cultura informática y defiende su naturaleza intrínseca como cartografías que muestran todas las contradicciones de la vida contemporánea bajo el capitalismo actual» (p. 17).

Desde la esfera de las ciencias, a finales de 1997, la analista de sistemas Donella H. Meadows publica en la revista Whole Earth su primer borrador sobre lo que ella identifica como puntos de intervención en sistemas complejos. Años más tarde, en 2009, se publica su texto Thinking in Systems: A Primer [Pensando en sistemas: una introducción] en el que la autora detalla este acercamiento analítico como marco general para pensar en diferentes tipos de sistemas: empresas, cuerpos vivos, micro y macroeconomías, ciudades, ecosistemas, etcétera. Meadows (2009) lista de menor a mayor el potencial de intervención de cada uno de los doce rasgos que ha identificado. En el apartado dedicado a los objetivos del sistema la autora expone que «los individuos que forman parte de un sistema a menudo no son capaces de reconocer a qué objetivo general del sistema están sirviendo» (Meadows, 2009, p. 161).

Existen lógicas procedurales concretas que refuerzan este tipo de situaciones en las que los individuos pierden la perspectiva de su condición global entretenidos en tareas que les reportan satisfacción inmediata, como hámsteres en la rueda, o como denominan diferentes autores desde las ciencias sociales, inmersos en un estado psicológico de flujo (Csikszentmihalyi, 1991), o en la zona (Schüll, 2012). Este tipo de propuestas que a nivel formal, desde disciplinas como el diseño de interacción o el diseño de juegos digitales, reciben el nombre de core loops (Cook, 2012; Lovell \& Fahey, 2012), se alimentan de estímulos que activan el sistema de recompensa del cerebro y consiguen que pongamos toda la atención en la actividad que los genera para poder volver a obtener esas recompensas inmediatas. Contextos digitales cotidianos como la aplicación de citas de cercanía Tinder son un claro paradigma de este tipo de dinámicas. Sus lógicas internas están vertebradas en una suerte de bucle compulsivo de corte atávico, que el autor Dori Adar (2014) ha denominado el bucle del cazador. Las fases básicas de este circuito según este autor son la localización de patrones por parte del individuo, la previsualización de la futura recompensa, algún tipo de acción mínima intermedia, la fase de anticipación, la gran acción significativa y la recompensa final. Esta 


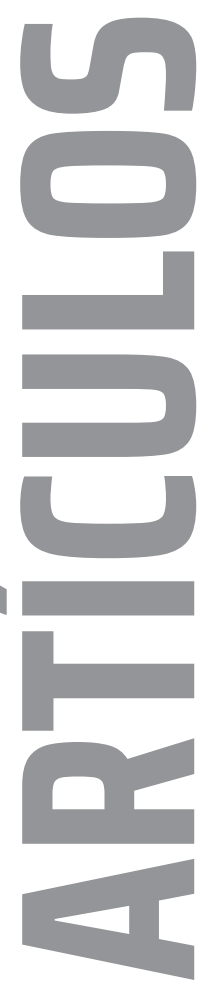

y otras tantas cadenas básicas de acciones mantienen a millones de personas conectadas al albor de las pantallas y sirven, de este modo, a los objetivos de poder de las grandes compañías de la economía digital. Para cuando los usuarios acceden a estos sistemas diseñados, muchas de las lógicas básicas integradas en ellos quedan ocultas y, como describe Bruno Latour (2016), funcionan como cajas negras cerradas y naturalizadas bajo una aparente neutralidad.

En este contexto la cuestión que guía y delimita esta investigación es cuál es la capacidad de los artistas de los nuevos medios y de los diseñadores de interacción para crear discurso disidente interviniendo, recreando o reconfigurando los relatos inscritos en estructuras sistémicas no naturales (sociales y/o artificiales). En concreto, qué diferentes modos de hacerlo podemos encontrar si seguimos la teoría de los puntos de intervención sobre sistemas complejos de la científica estadounidense Meadows.

Desde este contexto sistémico, el presente trabajo tiene como objetivo iniciar a cartografiar ciertas formas en torno a las prácticas artísticas y de diseño que reconfiguran los relatos normativos y que muestran compromiso, al poner en evidencia las políticas del establishment socioeconómico, político y cultural mediante la intervención en una serie de rasgos formales propios de las estructuras sistémicas.

Estas son las cuestiones centrales que se plantea este artículo y que invitan a enfocar y esbozar el panorama de los fenómenos de reconfiguración del relato que desde el ámbito artístico se está haciendo con relación a las lógicas, éticas, estéticas y políticas que subyacen en los sistemas no naturales, con el fin de contribuir en el conocimiento de diferentes modos de abordar el hecho crítico desde la práctica artística y de diseño.

\section{PRÁCTICAS CRÍTICAS}

El arte siempre ha tenido una fuerte vinculación con las tecnologías propias de cada época sin por ello apartar la vista de los posicionamientos críticos a diferentes niveles. En la conjunción de estas dos premisas, desde los años noventa con la expansión a nivel popular de tecnologías y herramientas en los contextos computacionales surgen movimientos de subversión y desobediencia como el de los Tactical Media (Boler, 2008; Critical Art Ensemble, 2001) que hacen uso crítico y teorizan las prácticas de los nuevos medios persiguiendo diferentes objetivos no comerciales y ontologías políticas potencialmente subversivas, alejadas de la cotidianidad de una socioeconomía capitalista y de mercado.

Parte del espíritu y de los conceptos de los Tactical Media siguen vigentes en la actualidad en prácticas de resistencia que desafían problemas políticos y sociales 


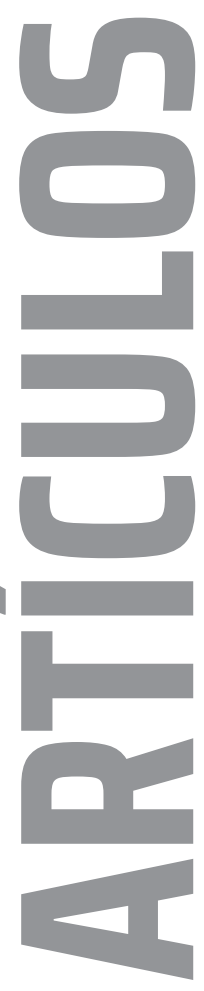

contemporáneos como las reflexiones y las evaluaciones sobre las infraestructuras de la vida cotidiana y los nuevos regímenes laborales (Crary, 2008), o las teorías elaboradas tras el uso creativo de las tecnologías de los nuevos medios en la erupción de los movimientos políticos del siglo XXI (Kluitenberg, 2011).

Desdeel diseño existen igualmente prácticas con forma de crítica y en muchos casos son descendientes directas de las propuestas de diseño especulativo de Anthony Dunne y Fiona Raby. Estos autores plantean una crítica a lo que ellos denominan diseño afirmativo (2013), el diseño que «refuerza el status quo» (p. 34), aquel que tiene un enfoque que se centra en la resolución de problemas, la innovación y el consiguiente consumo de bienes y servicios. Su propuesta de diseño crítico, por el contrario, ofrece conceptos opuestos, como objetos postóptimos y hostilidad hacia el usuario (Dunne, 2005), que buscan cuestionar y provocar, encontrar problemas y conducirnos hacia el pensamiento crítico.

En este sentido nos parece pertinente rescatar la más reciente discusión de Carl DiSalvo (2012) sobre diseño adversarial. Se trata de una forma de diseño crítico enfocada específicamente en tecnologías interactivas que "evoca e involucra cuestiones políticas» pero lo hace "a través de la conceptualización y la creación de productos y servicios y nuestras experiencias con ellos» (DiSalvo, 2012, p. 2). Esta creación activa de experiencia a través de productos funcionales es fundamental para el proyecto adversarial de DiSalvo. Especialmente relevante, dentro de las tácticas de diseño adversarial, es la noción de reconfiguración del remanente que el autor describe del siguiente modo:

\footnotetext{
La actividad de reconfigurar aprovecha los estándares de configuración, tanto a nivel técnico como social. Funciona manipulando esos estándares y abordando lo que queda fuera de las configuraciones comunes, a lo que se puede hacer referencia como el remanente (DiSalvo, 2012, p. 63).
}

El diseño adversarial fomenta el disenso, las relaciones de contestación y la generación de nuevas experiencias a través de artefactos diseñados y de su expresión.

Las cualidades estéticas, formales y relacionales de los sistemas que nos rodean incorporan órdenes y disposiciones que favorecen determinados intereses, convocan o excluyen diferentes colectivos, fomentan o dificultan ciertas acciones y comportamientos, y hacen más o menos contingentes ciertos modos de vida. Es irreal escindir estos sistemas de lo político, de lo social, de lo ético o de lo estético. Así, los tipos de prácticas que se describen a continuación discuten, ponen en entredicho y desobedecen agencias, lógicas o incluso ontologías asociadas a formas sistémicas convencionales. Ponen de manifiesto cómo, dado que los sistemas no naturales tienen política y sus ontologías son una forma particular
C Arte e Investigación

5 No 18 | NOVIEMBRE 2020 | ISSN 2469-1488 


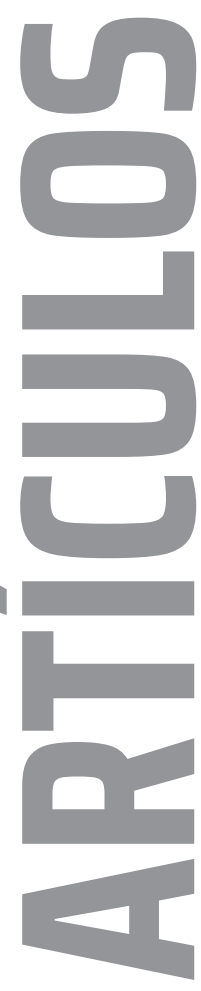

de crear mundo, la propia práctica basada en este tipo de estructuras tampoco escapa a esta dimensión política conflictiva.

\section{PUNTOS DE INTERVENCIÓN EN ESTRUCTURAS SISTÉMICAS}

De los doce rasgos formales descritos por Meadows (2009) como posibles puntos de intervención en sistemas vamos a revisar únicamente algunos de ellos, a saber: en el apartado Reglas de la casa, el quinto parámetro en el listado de Meadows relativo a las reglas del sistema, sus incentivos, castigos, restricciones, etcétera. En el punto Paquetes masivos de datos, el doceavo rasgo en importancia descrito por la autora es el referente a números, constantes, parámetros y valores del sistema. Y el último punto del cuerpo de este artículo, Lo menos cuantificable, se refiere al rasgo más importante, según Meadows, a la hora de intervenir sistemas, es decir, la mentalidad o paradigma que conduce y surge del sistema.

\section{REGLAS DE LA CASA}

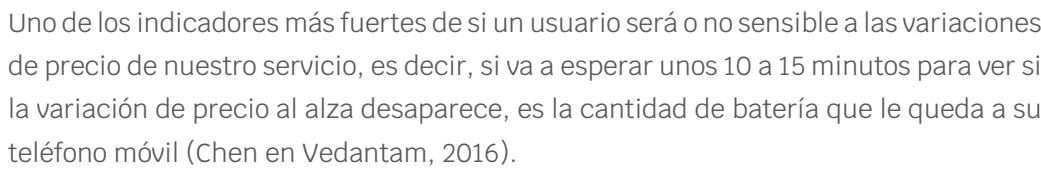

Estas declaraciones de Keith Chen, jefe de investigación económica de la empresa VTC Uber en mayo 2016, para la radio pública estadounidense NPR, dejan clara su política de penalización económica sobre la demanda de servicio. Cuando la demanda es alta, la compañía cobra dos, tres, incluso diez veces más de lo habitual por un viaje y si su algoritmo detecta un nivel bajo de batería el precio aumenta por la presunción de necesidad de urgencia del cliente. Los usuarios no están contentos con esta realidad, pero parece que no tanto como para dejar de usar el servicio. Estas tarifas dinámicas han ayudado a la compañía a convertirse en uno de los servicios de reserva de viajes en vehículo con conductor más importantes del mundo, a pesar de que sus políticas han dejado al descubierto debilidades éticas en situaciones de emergencia como catástrofes naturales o atentados terroristas.

Die With Me [Muere conmigo] (Depoorter, 2018) es un punto de conexión directa entre el mundo especulativo del diseño crítico que proponen Dunne y Raby (2013) (muy vinculado al diseño objetual) y el contexto más funcional del arte de los nuevos medios y el diseño computacional con agenda. El artista belga Dries Depoorter enuncia una nueva regla (de sistema) para el hecho cotidiano de quedarte sin batería en el móvil. Die With Me es una aplicación de chat por cercanía que solo puedes usar cuando tienes menos del $5 \%$ de carga en el móvil. Esa es la condición para ingresar en una sala de chat llena de personas con poca batería en la que podemos morir juntos en el camino hacia la paz de estar offline. Die With Me parte 


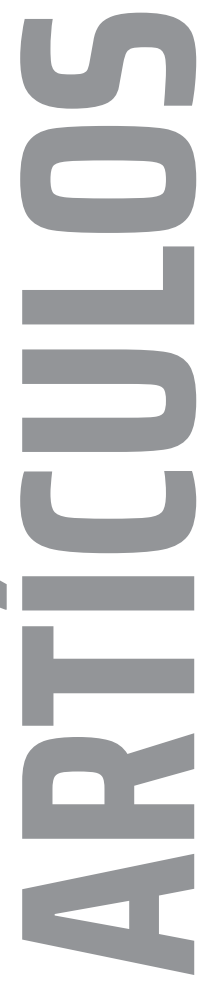

de una realidad social y da la vuelta a una condición que en el ámbito del diseño normativo de la app de Uber se usa como penalización. Depoorter convierte en un incentivo la lógica que el modelo económico y social está usando con propósitos únicamente comerciales utilitarios. Die With Me, además de su carácter poético, exuda una clara reflexión sobre la dependencia de mantener activos determinados estados del hardware.

\section{PAQUETES MASIVOS DE DATOS}

Los sistemas se alimentan de datos y aunque a nivel procedural se trate de uno de los puntos de intervención menos potentes según las teorías de Meadows (2009), sin duda acarrean semánticas sociales, culturales, económicas, políticas, éticas interesantes de revisar. En el ámbito de los algoritmos de inteligencia artificial los trainings sets, paquetes masivos de datos, son la base sobre la que se construyen los sistemas contemporáneos de aprendizaje automático y como tal resultan fundamentales para entender la forma en la que la inteligencia artificial está concibiendo el mundo.

El proyecto ImageNet (2010) es una gran base de datos visuales (fotografías) diseñada para su uso en la investigación de software de reconocimiento de objetos. Está compuesta por más de catorce millones de imágenes que han sido etiquetadas a mano utilizando diferentes servicios de crowdsourcing. Los sesgos en el etiquetado de imágenes son evidentes en esta base de datos. Dentro de la categoría \#personas hay ejemplos como los que siguen: una fotografía de una mujer que sonríe en bikini está etiquetada como «puta, zorra, desaliñada, ramera». Un joven que bebe cerveza se clasifica como «alcohólico, dipsomaníaco, borracho, mamado» (Crawford \& Paglen, 2019). Uno de los conjuntos de capacitación más ampliamente utilizados para el aprendizaje automático es a la vez un claro ejemplo de cómo las taxonomías y los sistemas de clasificación son políticos y en un porcentaje muy alto son reducciones que dejan fuera muchos matices $y$ variaciones.

Imagenet roulette (2019) es un proyecto de provocación concebido por Crawford y Paglen para poner de manifiesto cómo nuestros sesgos están siendo transmitidos en la Inteligencia Artificial. Cómo esa reducción que significa catalogar a las personas a partir de una fotografía de su rostro, deja evidencia de muchas debilidades. Crawford y Paglen visibilizan una cierta mentalidad dominante y unos supuestos no declarados que tristemente constituyen parte del paradigma actual de nuestra sociedad y ciertos conjuntos de creencias sobre cómo es nuestro mundo.

Consciente de las afecciones de los paquetes de datos generalistas, la artista británica Anna Ridler genera sus propios training sets como el que compone la pieza Myriad (Tulips) [Miríada (tulipanes)] (2018). Ridler toma diez mil fotos de tulipanes en el transcurso de la temporada de floración y categoriza cada una 


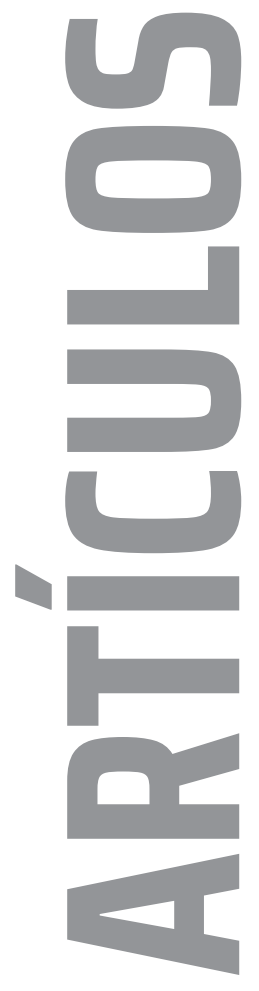

de ellas a mano. A partir de esta base de datos genera otras piezas: Mosaic Virus [Virus de mosaico] (2019a), una videoinstalación en la que la apariencia de los tulipanes que aparecen en los monitores está controlada por el precio en tiempo real del bitcóin, y Bloemenveiling (2019b), una subasta de tulipanes generados por inteligencia artificial en cadena de bloques.

Más allá de los posteriores usos que la artista hace de su propio data set, nos parece relevante destacar cómo ese gesto de composición del propio material fuente pone en cierto modo de relevancia la necesidad de ser conscientes de que la inteligencia artificial y los conjuntos de datos en los que se basa están siempre clasificados con cargas subjetivas, políticas, ideológicas. Como apuntan Crawford y Paglen (2019) en su ensayo se trata de conjuntos de datos que están configurando los límites epistemológicos que rigen la forma en la que operan los sistemas de inteligencia artificial y como tal deben formar parte esencial de las cuestiones socialmente significativas en torno a esta tecnología.

\section{LO MENOS CUANTIFICABLE}

Somos conscientes de habitar en tiempos de una sociedad obsesionada con los valores tangibles, que aprecia y persigue la cuantificación incluso de ámbitos difícilmente medibles como la ética, la libertad, el placer. Jake Elwes, artista afincado en Londres, recopila en su proyecto Dada Da Ta (2016) más de cincuenta horas de entrevistas en video con figuras destacadas de la industria tecnológica global, transcritas utilizando diferentes programas de reconocimiento de voz e identificación de términos numéricos, que dan como resultado una pieza de video que mantiene la cronología de la entrevista intacta pero reducida a un flujo de datos numéricos: «One, one billion, one million, one hundred million, two billion, one, two hundred, ten thousand...» [Uno, mil millones, un millón, cien millones, dos mil millones, uno, doscientos, diez mil ...] (Elwes, 2016, s. p.). Explica en la pieza de Elwes el cofundador de PayPal y Tesla Motors, Elon Musk, entre otros. El proyecto tiene un cierto tono paródico, a la vez que reflexivo, sobre el modelo de pensamiento predominante, evidenciando la situación contemporánea de nuestra sociedad cuantificadora. En un mundo altamente vinculado a lo computacional, sin embargo, podemos pensar en otros factores y propiedades generales de los sistemas, como la creatividad generativa, la diversidad, la resiliencia o la sostenibilidad de los mismos. El paradigma de cuantificación es reduccionista y seguramente debería ser revisado en muchos ámbitos. El cambio de paradigma es señalado por Meadows como el recurso más potente para generar cambios significativos en estructuras complejas, solo superado por un estado ideal en el que el individuo no se aferra a ningún paradigma conocido y fluye por encima de códigos determinados. La autora señala las propuestas de acción para el cambio de paradigmas que desde las ciencias expone el físico Thomas Kuhn (Kuhn y otros, 1994). Para poder modificar los grandes modelos de pensamiento se deben «señalar las anomalías y fallas en el viejo paradigma. Hablar y actuar, en voz 


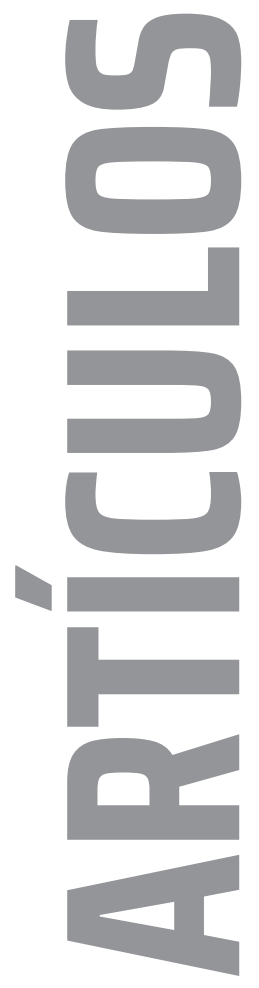

alta y con seguridad, desde el nuevo paradigma. Insertar personas con el nuevo paradigma en lugares de visibilidad pública y poder [...]» (Meadows, 2009, p. 164). Es ahí donde radica la importancia del trabajo de artistas y de diseñadores como agentes sociales que intervienen o reconfiguran los sistemas para evidenciar las deficiencias de los modelos culturales, económicos, éticos, políticos.

Adam Harvey es un investigador y artista estadounidense, afincado en Berlín, cuyo trabajo gira en torno a la visión inteligente por ordenador y los conceptos de privacidad y vigilancia relacionados con este tipo de tecnología. Su proyecto CV Dazzle (2010) es un tipo de camuflaje contra la visión computacional. Utiliza patrones diferenciales sobre el rostro de los individuos para desconcertar las características esperadas por los algoritmos de reconocimiento facial. Harvey reconfigura las lógicas de esta tecnología (el remanente) abordando lo que queda fuera de las lógicas comunes en el reconocimiento facial, evidenciando, entre otras cosas, el racismo subyacente en este contexto.

En otro tipo de esfera práctica, la instalación Letting Them Sleep [Déjalos dormir] (2017), del artista residente en Los Ángeles Stalgia Grigg, dinamita también algunas dinámicas normativas. En este proyecto de interacción los usuarios acceden a una pantalla de personalización de personajes y crean un avatar autorrepresentativo. Después de este proceso, el personaje que han creado se echa a dormir en la cama individual que está en el fondo del espacio representado en pantalla. Cuando un nuevo usuario se une al juego, el avatar actualmente dormido deja la pantalla para ser reemplazado por el nuevo personaje. El juego registra la puntuación en cifras de tiempo de los avatares y genera un listado de puntuaciones en una segunda pantalla. El desinterés de los posibles usuarios en el espacio físico donde se muestra este proyecto es la clave para lograr una puntuación más alta. Grigg rompe convenciones a varios niveles, desde el punto de vista del mundo del arte al poner en valor el desinterés del público asistente. Desde la perspectiva del diseño de interacción normativo al generar un ranking individual, sujeto a la inacción de los demás y usando dormir como acción principal del personaje de juego.

\section{CONCLUSIONES}

A lo largo de este artículo, se ha tratado de arrojar luz sobre algunos de los modos de acción crítica, intervención o reconfiguración que desde el ámbito del arte de los nuevos medios y del diseño de interacción desobediente se están llevando a cabo con relación a diversos tipos de sistemas no naturales, y que tratan de poner en crisis los valores distintivos, las disposiciones y las preocupaciones de la cultura y la sociedad contemporáneas.

La teoría de Meadows sobre los puntos de influencia nos ha servido como punto de partida a la hora de analizar cómo el arte y el diseño pueden cumplir una función 


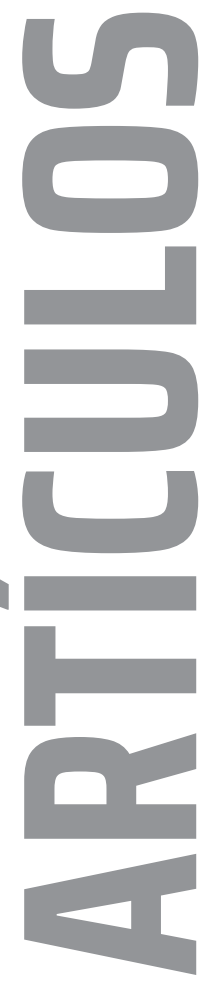

crítica de diferentes maneras. Cómo la figura del creador, como agente disidente, sirve como indicador de anomalías y debilidades de los paradigmas actuales de nuestra sociedad y, por tanto, como elemento de perturbación indispensable dentro de cualquier sistema. Cómo sus propuestas provocan preguntas y reflexión sobre el orden contemporáneo a través de la experiencia y la interpretación de sistemas de diferente escala y calado dentro del tejido social contemporáneo.

Tal y como queda expuesto en las anteriores páginas, se describen diferentes tipologías de práctica, que inciden en diversos rasgos formales y que nos pueden ayudar a sondear y revelar diversos dramas sociales y existenciales de nuestra vida cotidiana bajo la hegemonía de los modelos capitalistas. Los diferentes sistemas con los que nos relacionamos inscriben determinados imaginarios, reglas, valores, representaciones y expectativas acerca de nuestros papeles, responsabilidades, identidades, contextos. En este sentido, las prácticas descritas tratan de desafiar esta suerte de forma de gobierno que de manera sorda estructura nuestras cotidianidades y posibilidades vitales.

Los sistemas normativos, que en cierta medida devienen en agentes cocreadores de nuestras realidades, presentan diferentes reformulaciones bajo la perspectiva de artistas y diseñadores críticos. Las decisiones de reconfiguración de los autores expuestos en esta investigación apuntan hacia diferentes fenómenos sintomáticos de nuestra sociedad: la asimilación por parte de las nuevas formas del sistema capitalista de esos territorios históricos de subversión contra la productividad que eran el descanso, la inacción, el retiro, la pausa; la normalización de la mercantilización de esas y de otras experiencias individuales; los sesgos de pensamiento en muchos ámbitos de la esfera tecnológica tanto pública como privada del individuo; la fiebre de la cuantificación, etcétera. La reconfiguración que de todas estas realidades se hace desde los contextos del arte y el diseño se relaciona específicamente con situaciones sociales y propuestas de diseño afirmativo creando experiencias críticas interactivas y/o extensiones del material o la realidad de partida. En algunos casos los proyectos se plantean desde la alteridad del sistema de referencia (como Dada Da Ta), reconfigurando el remanente como define DiSalvo (Die With Me); en otros, utilizando o interviniendo los propios sistemas sobre los que reflexionan (CV Dazzle o Imagenet Roulette). Así pues, el trabajo trata de dar cuenta de cómo estas prácticas que desafían los sistemas regulares, que incorporan configuraciones políticas particulares, demuestran la capacidad de influencia, el papel y la misión del artista como agente de cambio social y cultural.

\section{REFERENCIAS}

Adar, D. (2014). The Secret of Tinder [El secreto de Tinder] [Entrada de blog]. Recuperado de https://www.doriadar.com/2014/12/18/the-secret-of-tinder/ 
Boler, M. (Ed.). (2008). Digital media and democracy: Tactics in hard times. Londres, Inglaterra: MIT Press.

Cook, D. (30 de abril de 2012). Loops and Arcs [Bucles y arcos] [Entrada de blog]. Recuperado de https://lostgarden.home.blog/2012/04/30/loops-and-arcs/

Crary, J. (2008). Sobre los finales del sueño: Sombras en el resplandor de un mundo 24/7. Estudios visuales, 5, 8-21.

Crawford, K. y Paglen, T. (2019). Excavating Al: The Politics of Training Sets for Machine Learning. Recuperado de https://www. excavating.ai/

Critical Art Ensemble. (Ed.). (2001). Digital resistance: Explorations in tactical media [Resistencia digital: exploraciones en medios tácticos]. Autonomedia.

Csikszentmihalyi, M. (1991). Flow: The Psychology of Optimal Experience [Estado de flujo: la psicología de la experiencia óptima]. Nueva York, Estados Unidos: Harper Collins.

Deleuze, G. (1992). Postscript on the Societies of Control [Posdata sobre las sociedades de control]. October, 59, 3-7.

Depoorter, D. (2018). Die With Me [Muere conmigo]. Disponible en https://driesdepoorter be/diewithme/

DiSalvo, C. (2012). Adversarial design [Diseño de confrontación]. Cambridge, Estados Unidos: MIT Press.

Dunne, A. (2005). Hertzian tales: Electronic products, aesthetic experience, and critical design [Cuentos hertzianos: productos electrónicos, experiencia estética y diseño crítico]. Cambridge, Estados Unidos: MIT Press.

Dunne, A. y Raby, F. (2013). Speculative everything: Design, fiction, and social dreaming [Especulativo general: diseño, ficción y sueños sociales]. Cambridge, Estados Unidos: MIT Press.

Elwes, J. (2016). Dada Da Ta. Disponible en https://www.jakeelwes.com/project-DaDaTa. html

Galloway, A. R. (2006). Gaming: Essays on algorithmic culture [Gaming: ensayos sobre cultura algorítmica]. Mineápolis, Estados Unidos: University of Minnesota Press.

Grigg, S. (2017). Letting Them Sleep [Déjalos dormir]. Disponible en http://stalgiagrigg. name/a_img/2017/17.mp4

Harvey, A. (2010). CV Dazzle. Disponible en https://ahprojects.com/cudazzle/

ImageNet. (2010). ImageNet. Disponible en http://www.image-net.org/

Kluitenberg, E. (2011). Legacies of tactical media: The tactics of occupation: from Tompkins Square to Tahrir [El legado de los medios tácticos: tácticas de ocupación: de la plaza Tompkins a Tahrir]. Ámsterdam, Holanda.

Kuhn, T. S., Neurath, O. y Dewey, J. (1994). The Structure of scientific revolutions [La estructura de las revoluciones científicas]. Chicago, Estados Unidos: University of Chicago Press.

Latour, B. (2016). La esperanza de Pandora: Ensayos sobre la realidad de los estudios de la ciencia. Barcelona, España: Gedisa.

Lovell, N. y Fahey, R. (2012). Design Rules for Free-to-Play Games [Reglas de diseño para juegos Free-to-Play]. Londres, Inglaterra: GAMESbrief. 


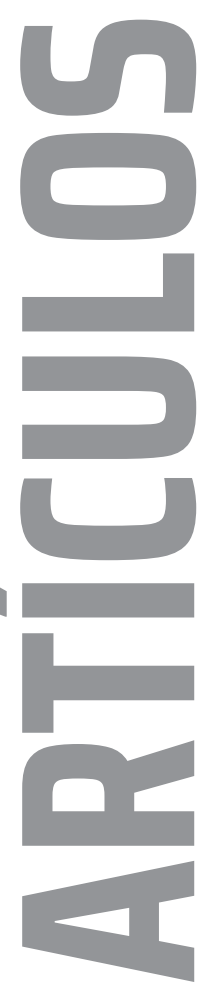

Manovich, L. (2001). The language of new media [El lenguaje de los nuevos medios]. Cambridge, Estados Unidos: MIT Press.

Meadows, D. H. (2009). Thinking in systems: A primer. [Pensando en sistemas: una introducción]. Londres, Inglaterra: Earthscan.

Miller, J. H. y Page, S. E. (2007). Complex adaptive systems: An introduction to computational models of social life [Sistemas adaptativos complejos: una introducción a los modelos computacionales de la vida social]. Nueva Jersey, Estados Unidos: Princeton University Press.

Murray, J. H. (1997). Hamlet on the holodeck: The future of narrative in cyberspace [Hamlet en la holocubierta: el futuro de la narrativa en el ciberespacio]. Nueva York, Estados Unidos. Free Press.

Ridler, A. (2018). Myriad (Tulips) [Miríada (tulipanes)]. Disponible en http://annaridler. com/myriad-tulips

Ridler, A. (2019b). Bloemenveiling. Disponible en https://bloemenveiling.bid/

Ridler, A. (2019a). Mosaic Virus [Virus de mosaico]. Disponible en http://annaridler.com/ mosaic-virus

Schüll, N. D. (2012). Addiction by design: Machine gambling in Las Vegas [Adicción por diseño: juegos de azar en Las Vegas]. Nueva Jersey, Estados Unidos: Princeton University Press.

Vedantam, S. (17 de mayo de 2016). This Is Your Brain On Uber [Este es tu cerebro en Uber] [Entrada de blog]. Recuperado de https://www.npr.org/2016/05/17/478266839/ this-is-your-brain-on-uber?t=1581500268385\&t=1595333550130 